\title{
Geophysical Techniques for Plant, Soil, and Root Research Related to Sustainability
}

\author{
Giovanni Bitella, Roberta Rossi, Antonio Loperte, Antonio Satriani, \\ Vincenzo Lapenna, Michele Perniola, and Mariana Amato
}

\begin{abstract}
The sustainable management of human activities, from production to waste disposal and the cycling of finite resources, is one of the great challenges of research for the coming decades, stemming from societal needs and the growing awareness of environmental mechanisms.

Research on geophysical methods provides an interdisciplinary approach to such challenges by addressing the need for techniques to assist in designing and monitoring strategies for sustainability in agriculture and other environment-related sciences.

In the past few decades, technological advances have produced new tools or have improved existing techniques for near-surface geophysical investigation in a robust, cost-effective, and noninvasive way. Experimental results have proved that soil physical properties thus detected and mapped can be used as a proxy of physical, chemical, and biological features relevant for the appropriate management of soils, based on their behavior, spatial variability, and time dynamics.

This chapter reviews principles of the techniques and reports selected research results on environmental and agronomic research.
\end{abstract}

\footnotetext{
G. Bitella $\bullet$ M. Perniola $\bullet$ M. Amato $(\bowtie)$

Scuola di Scienze Agrarie, Forestali, Alimentari ed Ambientali (SAFE), Università degli Studi della Basilicata (UNIBAS), Via Ateneo Lucano 10, 85100 Potenza (PZ), Italy

e-mail:mariana.amato@unibas.it

R. Rossi (四)

CRA Consiglio per la ricerca in agricoltura e l'analisi dell'economia agraria, Rome, Italy

e-mail: roberta.rossi@entecra.it
}

\author{
A. Loperte • A. Satriani • V. Lapenna \\ CNR-IMAA Consiglio Nazionale delle Ricerche. Istituto di Metodologie per 1'Analisi \\ Ambientale, C.da Santa Loja Tito Scalo, 85050 Potenza, Italy
}




\section{Introduction}

Research in the coming decades faces challenges stemming from the most urgent needs of society, from a growing population to the reduced availability of important resources and problems in cycling of renewable ones. Among them pursuing sustainability plays a key role and requires the knowledge of environmental mechanisms and the ability to monitor the impact of strategy implementation. The concept of "sustainable agriculture" well identifies the relationship between agriculture and environment, with the specific challenge to produce sufficient food and fiber, as well as raw materials for "green chemistry" with acceptable environmental costs and to manage difficult environments while preserving and enhancing the amount and quality of environmental resources. The integration of the environmental concerns into agricultural policy is the key strategy for enhancing the sustainability of agro-ecosystems (EEA Report 2013). This relationship is more evident if we consider the increasing frequency of the climate-related hazards and the role of the agriculture in the climate adaptation strategies (see IPCC Report 2014 by Field et al. 2014).

The arena where agricultural land use and environmental processes meet is the soil: the thin upper part of Earth Crust (Earth Skin) represents one of the more complex systems in which lithosphere, hydrosphere, and biosphere interact and are strongly linked. The thickness of the zone beneath the Earth surface that is of interest for the agriculture science is within the range $0-2 \mathrm{~m}$. There is a growing demand of near-surface observing technologies for studying a wide spectrum of phenomena in the soil having implications on agriculture and environment, from the analysis of time-dependent change of water content to the detection of pollutants and from the analysis of soil salinization and fertility to the study of soil-root plant interactions (Allred et al 2008; Vereecken et al. 2006).

Geophysics addressed these challenging themes with novel observing technologies based on completely innovative sensors (i.e., optical fibers, electromagnetic devices), advanced algorithms for $2 \mathrm{D}$ and $3 \mathrm{D}$ tomographic imaging, and new technologies for field surveying (i.e., drones and Land Unmanned Vehicles). To date, geophysics provides a set of robust, cost-effective, and completely noninvasive or minimally invasive technologies for near-surface investigations able to estimate the physical properties of the shallow layers of soil and subsoil.

Such technologies are used in a range of applications, from archaeology to hydrology or precision agriculture, and allow to acquire information that can be directly used for the description and monitoring of relevant features or can guide strategies for sampling (Rossi et al. 2011).

Research on geophysical applications in agriculture and the environment has been conducted in Basilicata in the past decade, and this chapter provides an introduction to the techniques and an overview of selected results obtained within this context. 


\section{Principles of Geophysical Techniques for Agriculture and the Environment}

Sheriff (1991) has defined "applied geophysics" as: "making and interpreting measurements of physical properties of the earth to determine subsurface conditions, usually with an economic objective, e.g., discovery of fuel or mineral depositions." By working at different scales, geophysical methods may be applied to a wide range of investigations. The geophysical exploration methods or geophysical surveying measurements within geographically restricted areas are used to determine the distributions of physical properties at depths that reflect the local subsurface geology.

There is a broad division of geophysical surveying methods into those that make use of natural fields of the Earth and those that require the input into the ground of artificially generated energy. The natural field methods utilize the gravitational, magnetic, electrical, and electromagnetic fields of the Earth, searching for local perturbations that may be caused by concealed subsurface features. Artificial source methods involve the generation of local electrical or electromagnetic fields that may be used like natural fields or, in the most important single group of geophysical surveying methods, the generation of seismic waves whose propagation velocities and transmission paths through the subsurface are mapped to provide information on the distribution of geological boundaries at depth. Generally, natural field methods can provide information on Earth properties at greater depths and are logistically more simple to carry out than artificial source methods.

The basic physical principles are quite simple: an energizing source, generally located on the surface, sends a primary signal (i.e., elastic waves, electromagnetic pulse) into the ground and a receiving system detects a secondary signal generated by the interaction between the soil and the primary signal. The analysis of the geophysical signals measured by means of the receiving system allows us to reconstruct the spatial pattern of the physical properties of the subsoil (i.e., density, electrical resistivity, electrical permittivity). In absence of an artificially generated signal, the geophysical methods are identified as passive and the sensors can only detect the fluctuations of the natural geophysical field (magnetic, electric, gravimetric). The investigation depth and the spatial resolution of the geophysical methods are strictly connected to the frequency of the energizing signal and to the electrodic distance between the transmitting and receiving sensors (Steeples 2001).

As the range of applications of geophysical methods has increased, the subdiscipline of "environmental geophysics" has been defined as follows: "The application of geophysical methods to the investigation of near-surface physicochemical phenomena which are likely to have (significant) implications for the management to the local environment" (Greenhouse 1991; Steeples 1991).

A wide range of geophysical surveying methods applied to environmental problems exists, for each of which there is an "operative" physical property to which the method is sensitive. Methods are listed in Table 1. 
Table 1 Geophysical methods

\begin{tabular}{l|l|l}
\hline Method & Measured parameter & Operative physical property \\
\hline Seismic & $\begin{array}{l}\text { Travel times reflected/refracted } \\
\text { seismic waves }\end{array}$ & $\begin{array}{l}\text { Density and elastic moduli, which deter- } \\
\text { mine the propagation velocity of seismic } \\
\text { waves }\end{array}$ \\
\hline Gravity & $\begin{array}{l}\text { Spatial variations in the strength } \\
\text { of the gravitational field of the } \\
\text { earth }\end{array}$ & Density \\
\hline Magnetic (Mag) & $\begin{array}{l}\text { Spatial variations in the strength } \\
\text { and of the geomagnetic field }\end{array}$ & Magnetic susceptibility \\
\hline $\begin{array}{l}\text { Electrical } \\
\text { resistivity }\end{array}$ & Earth resistance & $\begin{array}{l}\text { Electrical resistivity } \rho \\
\text { Electrical conductivity (EC) }\end{array}$ \\
\hline $\begin{array}{l}\text { Induced } \\
\text { polarization }\end{array}$ & $\begin{array}{l}\text { Polarization voltages or } \\
\text { frequency-dependent ground } \\
\text { resistance }\end{array}$ & Electrical capacitance \\
\hline $\begin{array}{l}\text { Self-potential } \\
\text { (SP) }\end{array}$ & Electrical potentials & Electrical conductivity (EC) \\
\hline Electromagnetic & Response to electromagnetic & $\begin{array}{l}\text { Electrical conductivity (EC) and } \\
\text { inductance }\end{array}$ \\
\hline Radar & $\begin{array}{l}\text { Travel times of reflected radar } \\
\text { pulses }\end{array}$ & Dielectric constant \\
\hline
\end{tabular}

Geophysical methods are often used in combination because in the phase of interpretation the ambiguity arising from the results of one survey method may often be resolved based on results from another method. The main fields of application of geophysical surveying and the most appropriate surveying methods are listed in Table 2.

Geophysical imaging techniques offer high spatiotemporal resolution combined with a noninvasive character and are a very attractive tool for soil characterization without disturbance (Michot et al. 2003; Samouelian et al.. 2003; al Hagrey 2007; Besson et al. 2010).

Among the numerous techniques, electrical and electromagnetic methods are most often used, and we will describe some of them, with emphasis on methods which have been used in case studies from research teams in Basilicata.

Self-Potential and Magnetometry are passive methods based on measurements of electrical and magnetic natural fields carried at the earth surface. They are the oldest geophysical methods and have been first applied using purely qualitative approaches. Nowadays, thanks to novel algorithms for tomographic data inversion, these old methods are becoming modern tools for innovative application in hydrogeophysics and environmental sciences (Chianese and Lapenna 2007; Soueid Ahmed et al. 2013). The SP method is a very promising tool for studying the waterplant root interactions, while the Mag method is suitable for mapping the presence of heavy metal in soil.

Electrical conductivity (ECa) or its inverse resistivity (ER) is one of the most utilized variable to indirectly assess soil spatial variability in agricultural fields (Corwin and Plant 2005). 
Table 2 Main fields of application and relevant methods of geophysical survey

\begin{tabular}{l|l}
\hline Application & Appropriate survey methods* \\
\hline Exploration for fossil fuels (oil, gas, coal) & $\mathrm{S}, \mathrm{G}, \mathrm{M},(\mathrm{EM})$ \\
\hline Exploration for metalliferous mineral deposits & $\mathrm{M}, \mathrm{EM}, \mathrm{E}, \mathrm{SP}, \mathrm{IP}, \mathrm{R}$ \\
\hline Exploration for bulk mineral deposits (sand and gravel) & $\mathrm{S},(\mathrm{E}),(\mathrm{G})$ \\
\hline Exploration for underground water supplies & $\mathrm{E}, \mathrm{S},(\mathrm{G}),(\mathrm{Rd})$ \\
\hline Engineering/construction site investigation & $\mathrm{E}, \mathrm{S}, \mathrm{Rd},(\mathrm{G}),(\mathrm{M})$ \\
\hline Archaeological investigations & $\mathrm{Rd}, \mathrm{E}, \mathrm{EM}, \mathrm{M},(\mathrm{S})$ \\
\hline Agriculture & $\mathrm{G}, \mathrm{M}, \mathrm{S}, \mathrm{EM}, \mathrm{E}, \mathrm{SP}, \mathrm{IP}, \mathrm{R}, \mathrm{Rd}$ \\
\hline
\end{tabular}

$G$ gravity, $M$ magnetic, $S$ seismic, $E$ electrical resistivity, $S P$ self-potential, $I P$ induced polarization, $E M$ electromagnetic, $R$ radiometric, $R d$ ground-penetrating radar. Subsidiary methods in brackets.

Source: Kearey et al. (2002)—An introduction to geophysical exploration (modified)

The techniques commonly used to measure the ECa variation within the root zone at field scale are essentially two: Electrical resistivity (ER) and Electromagnetic induction (EMI).

EMI methods use dual coil systems in which a transmitter coil is used to generate a primary electromagnetic field. When this electromagnetic field travels through the soil, eddy currents are generated as a function of soil conductivity, and this produces a secondary magnetic field which is detected by the receiving coil together with the primary magnetic field.

Electrical conductivity is then calculated as a function of the difference between the primary and the secondary magnetic fields. The explored soil volume is function of: the distance between transmitting and receiving coils, coils' operating frequency, coils' orientation, and distance from the soil.

The first applications in agriculture were on soil water (Edlefsen and Anderson 1941) and salinity (Rhoades and Ingvalson 1971), but a major diffusion of the technique in the 1980s is linked to the development of precision agriculture, based on optimization of agricultural management within a field. Technologically, this was also made possible by the growing availability of GPS which allowed the use in dynamic mode. Electromagnetic tools are easy to carry in the field and do not require contact with soil, therefore horizontal variations are easily mapped even in harsh environments (frozen/dry soil), during the cropping season by lifting the instruments above the canopy or with crop residues covering the soil surface (Brevik et al. 2003). Characterizing electrical conductivity in the soil profile, though, is not simple, given the nonlinear relation between EC and depth (with few exceptions). This requires complex processing of data (Corwin and Lesch 2005). Furthermore, calibration is not easy; it is time consuming and needs to be repeated in case of lengthy measurements, since readings are affected by air temperature (Dabas and Tabbagh 2003). Also, metals interfere with magnetic fields, and metallic objects in measurement areas may totally prevent a campaign.

DC Electrical Resistivity (ER) methods are widely used in agricultural and environmental sciences and allow to overcome some of the limitations of other methods as far as calibration and profile characterization are concerned $<\mathrm{Q}>$. 
The most appropriate methods for obtaining information on the variability of the electrical resistivity of the subsoil are the Electrical Resistivity Tomography (ERT) and the Automated Resistivity Profiling (ARP). The ERT methods are able to describe the resistivity pattern at different levels of depth in subsoil, while the ARP is an optimal tool for the fast resistivity surveying of large areas.

The working principle of the ERT is the injection of a known DC electric current into the subsurface through an array of transmitting electrodes and in the subsequent measurement of the voltage difference with an array of receiving potential electrodes. In this way, ERT is able to provide information about the spatial distribution of the electrical resistivity (i.e., the electrical conductivity) in the subsoil.

The electrical resistivity tomography of subsurface investigation is based on the variability of resistance to the conductance of electrical current, in subsurface materials, depending on variations in moisture content, density, and chemical composition. In electrical resistivity investigation, an electrical current [I (mA)] is applied through two current electrodes, and the potential difference $[\Delta \mathrm{V}(\mathrm{mV})]$ between two or more potential electrodes is measured to detect the resistivity of the material at depth. In order to reduce electrode polarization effects, which could affect the accuracy of the measure, the injected current is modulated as a low-frequency square or sinusoidal wave. There are several possible electrode arrangements, and Fig. 1 depicts the most used ones, which are the Wenner, Schlumberger, and dipole-dipole arrays.

Whichever the used array, the ERT is based on the measure of the ground electrical potential while the current is injected. In this way, it is possible to calculate the apparent resistivity $(\rho a)$ :

$$
\rho a=K\left(\frac{\Delta V}{I}\right)
$$

where $\rho a$ is expressed in $\Omega \mathrm{m}$ and $K$ is a geometrical factor depending on the adopted array configuration (Fig. 1). The spatial arrangement of measured soil volumes depends on the position of the electrodes at the surface and on the used array configuration (Edwards 1977).

The choice of the array configuration depends on the site features as well as on depth, size, and composition of the target as well as on the desired signal/noise ratio. Details about array configurations and their sensitivity functions are reported in Loke (2001). Modern georesistivimeters have multielectrode systems able to acquire a large number of data by automatically switching quadrupoles for each array, which is composed of a consistent number of electrodes properly fitted on the ground. All possible quadrupole spacings along the line are used for measurements, from the lowest-corresponding to adjacent electrodes-to maximum spacing, determined by the total array length. 


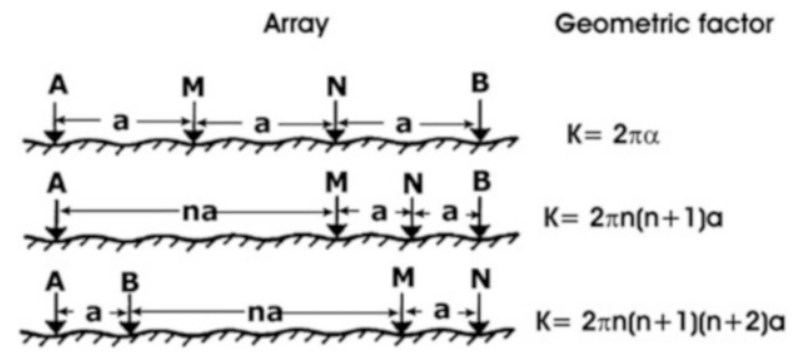

Fig. 1 Some common collinear electrode configurations for resistivity studies. A-B: current electrodes; $\mathrm{M}-\mathrm{N}$ : potential electrodes; a: electrode spacing; $\mathrm{k}$ : geometric factor; $\mathrm{n}$ : ratio of the distance between the A-M electrodes and the A-B dipole spacing

Processing of data with numerical methods then allows to reconstruct the heterogeneous spatial distribution of resistivity in the subsurface. This distribution can be represented as 2D or 3D tomograms (Loke and Barker 1996) (Fig. 2).

The continuous or automatic profiling of resistivity is an extremely fast and costeffective tool for mapping the horizontal spatial variability of the apparent resistivity in large areas. Two devices have been developed for applications in agriculture: the ARP (ARP (C), Geocarta, Paris) in France and Veris 3100 (Veris Technologies, Salina, KS) in the USA.

The ARP (Automatic Resistivity Profiling-Fig. 3) is an evolution of the Mucep (Panissod et al. 1997), developed in France by CNRS and the University of Paris IV since 1979. It is a multielectrode system which measures at three soil levels simultaneously $0-50,0-100,0-200 \mathrm{~cm}$ from the soil surface. The system is designed to be used on-the-go, towed in the field, and has a V-shaped 2D geometry (defined "vol-de-canard" by Panissod et al. 1997) where rolling electrodes are teethed wheels. A doppler radar is coupled with a GPS and positioned on the device to provide precise positioning.

The spatial information collected by the ARP system is used for positioning measurements but also for computing a DEM (Digital Elevation Model) providing topographic attributes such as slope and position that facilitate the interpretation of resistivity variation and the definition of management zones (Rossi et al. 2013a).

The Veris system uses a linear geometry with a Wenner array and explores two soil layers: 0-30 and 0-90 cm from the soil surface. Electrodes are metal discs.

The ground-penetrating radar (GPR) is an active electromagnetic technique and nondestructive for physical detection, which utilizes similar principles to the reflection seismic method.

An electromagnetic pulse in the range of $10 \mathrm{MHz}$ to $1 \mathrm{GHz}$ is radiated by a transmitting antenna and propagates through the soil to be investigated, and a receiving antenna gathers the backscattered signal engendered by hidden targets, i.e., anomalies arising into the electromagnetic features of the surveyed medium. The result of a single GPR measurement is a trace where the amplitude of the backscattered field is represented along the two-way-travel time (Fig. 4). 


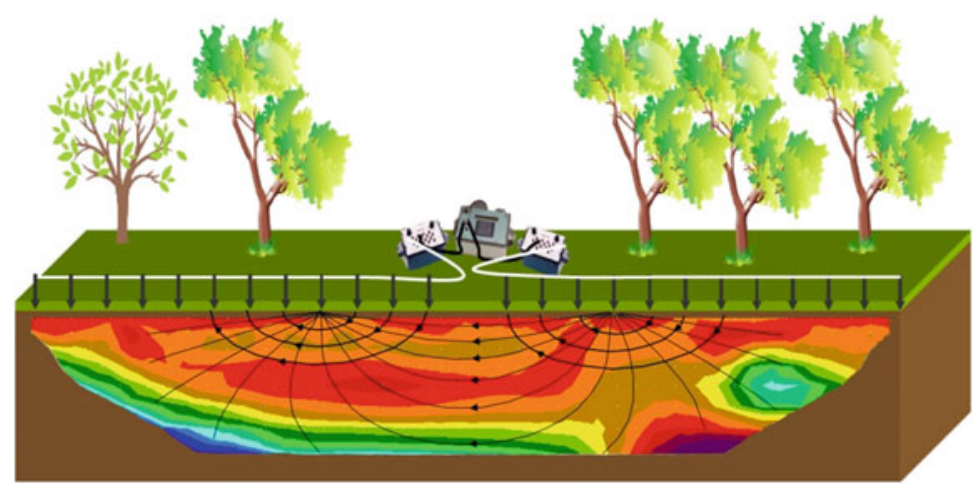

Fig. 2 Representation of a 2D section of soil resistivity obtained after data inversion with numerical modeling

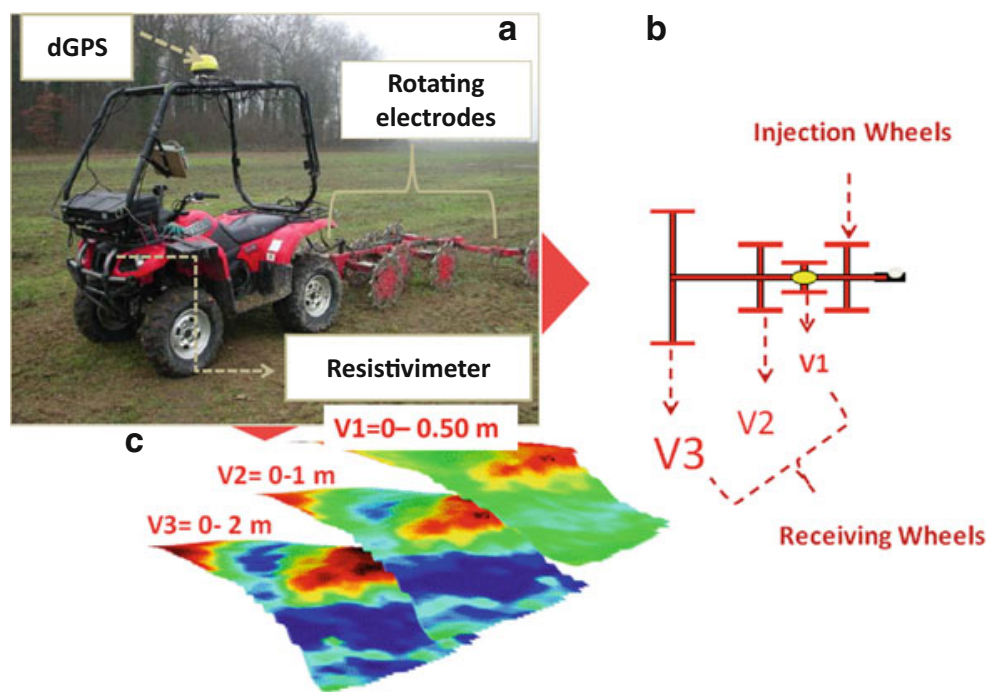

Fig. 3 (a) Picture of the on-the-go resistivity meter (ARP $\mathbb{C}$, Automatic Resistivity Profiling, Geocarta, Paris, France) trained by a filed vehicle; (b) schematic representation of the multiple rotating electrode system; and (c) maps of soil electrical resistivity distribution at the three consecutive exploration depths $(V 1=0-0.5 \mathrm{~m} ; V 2=0-1 \mathrm{~m} ; V 3=0-2 \mathrm{~m})$

Accordingly, the outcome of the GPR survey is a radargram built as the superposition of the time traces collected at the single measurement points (Daniels 2004)

The velocity at which the EM energy travels in the ground depends on the material. If the velocity of the propagated EM wave was known, then the depth of wave reflection can be obtained as: 


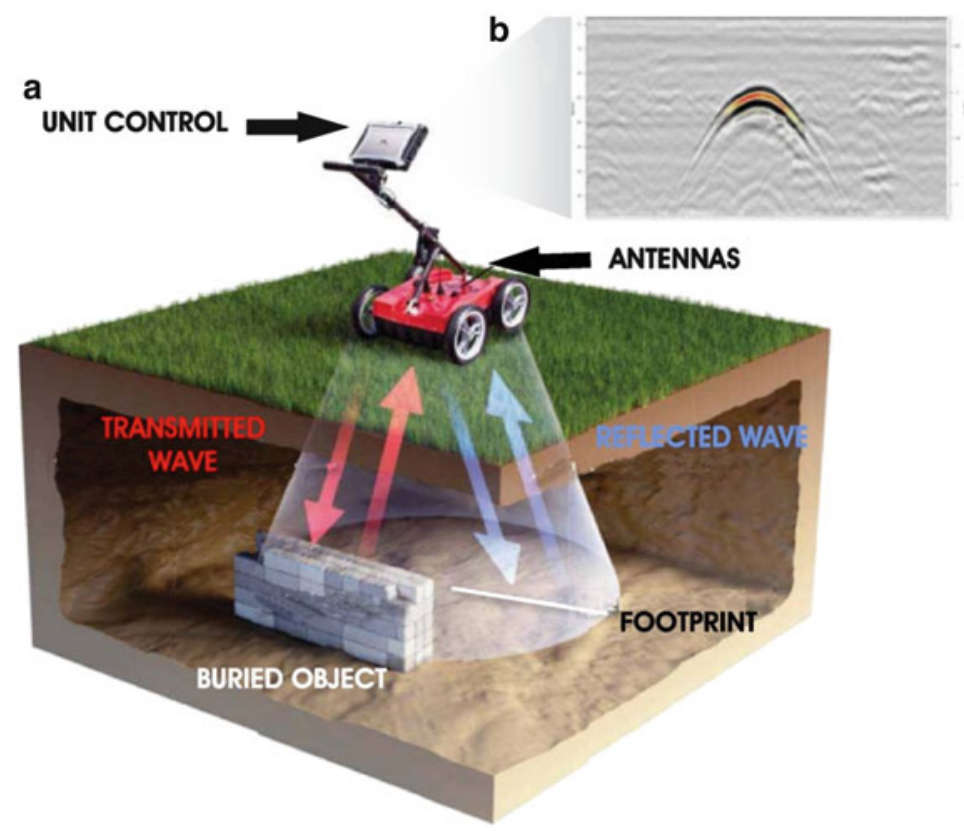

Fig. 4 Schematic representation of the GPR working principle (a) manual data acquisition system; (b) raw-data radargram

$$
d_{\mathrm{r}}=\frac{V t_{\mathrm{r}}}{2}
$$

where $d_{\mathrm{r}}=$ depth of wave reflection; $V=$ velocity of EM wave; and $t_{\mathrm{r}}=$ time range of the wave propagating path and reflecting path, and $V$ denotes the velocity of electromagnetic signal into the probed medium. Such a velocity depends on the relative dielectric permittivity $\left(\varepsilon_{\mathrm{r}}\right)$ of the surveyed medium:

$$
V=\frac{c}{\sqrt{\varepsilon_{\mathrm{r}}}}
$$

$c$ being the speed of light in vacuum, which can be approximated to $0.3 \mathrm{~m} / \mathrm{ns}$. The relative dielectric permittivity can be estimated by using direct or indirect methods (Conyers and Goodman 1997; Daniels 2002), and its values for several materials encountered in geological surveys are given in Table 3.

Data can be collected along arrays by dragging antennas on the ground.

In recent years, research efforts have been done for implementing advanced data processing based on addressing GPR data processing as an inverse electromagnetic scattering problem. This gives better results in determining target location and geometric features (Soldovieri et al. 2011). 
Table 3 Relative dielectric permittivity of geologic materials measured at $100 \mathrm{MHz}$

\begin{tabular}{l|l|l|l}
\hline Material & $\begin{array}{l}\text { Relative dielectric } \\
\text { permittivity }\left(\varepsilon_{\mathrm{r}}\right)\end{array}$ & Material & $\begin{array}{l}\text { Relative dielectric } \\
\text { permittivity }\left(\varepsilon_{\mathrm{r}}\right)\end{array}$ \\
\hline Air & 1 & Shale & $5-15$ \\
\hline Dry sand & $3-5$ & Clay & $5-40$ \\
\hline Dry silt & $3-30$ & Concrete & 6 \\
\hline Ice & $3-4$ & Saturated silt & $10-40$ \\
\hline Asphalt & $3-5$ & Dry sandy coastal land & 10 \\
\hline $\begin{array}{l}\text { Volcanic } \\
\text { ash/pumice }\end{array}$ & $4-7$ & $\begin{array}{l}\text { Average organic-rich } \\
\text { surface soil }\end{array}$ & 12 \\
\hline Limestone & $4-8$ & Marsh or forested land & 12 \\
\hline Granite & $4-6$ & $\begin{array}{l}\text { Organic-rich agricul- } \\
\text { tural land }\end{array}$ & 15 \\
\hline Permafrost & $4-5$ & Saturated sand & $20-30$ \\
\hline Coal & $4-5$ & Freshwater & 80 \\
\hline
\end{tabular}

\section{Applications and Case Studies in Agriculture and the Environment}

The EM and ERT methods have been largely applied in agriculture and environmental studies, from monitoring of saltwater intrusion in coastal areas to the diffusion of pollutants in groundwater; the time-dependent change of soil water content; the surveying of plant root biomass (Amato et al. 2008); the analysis of water-soil-root plant interactions and many other significant applications (Werban et al. 2008; Calamita et al. 2012).

The ARP is increasingly used in precision farming (viticulture) giving contributes for improving the management strategies aimed to improve and enhance the quality of the crop production (Rossi et al. 2013a).

The GPR method can be applied to a wide range of agriculture and environmental problems such as the detection of pollutant leakage in groundwater, the mapping of the root-plant geometry, and the rapid mapping of soil water content. Recently, novel applications in precision farming have been carried out using advanced system of semi-automatic vehicles for GPR data acquisition (Hubbard et al. 2002; Rubin 2006).

A case study where a combination of techniques was used in an agricultural field to highlight variation at different scales regards a study in a wheat field located at Gaudiano-Lavello-Basilicata (41 $\left.{ }^{\circ} 6^{\prime} 6^{\prime \prime} \mathrm{N}, 15^{\circ} 50^{\prime} 55^{\prime \prime} \mathrm{E}\right)$, managed by ALSIA (Agenzia Lucana di Sviluppo ed Innovazione in Agricoltura). The field subjected to two tillage management (conventional tillage at $35 \mathrm{~cm}$ and sod seeding) from 3 years.

On-the-go multi-depth resistivity meter (ARP C), Geocarta, Paris) (Rossi et al. 2013a) was used to measure simultaneously at three different depths that correspond to the distance between receiving wheels $(V 1=0.50 \mathrm{~m}, V 2=1 \mathrm{~m}$, $V 3=2 \mathrm{~m})$. Data were real time referenced by DGPS. Data were collected on 
2.16 ha along parallel transects $4 \mathrm{~m}$ distant between each other. A total number of 59,376 measurements were taken. The entire area was surveyed in about $40 \mathrm{~min}$ at an average speed of $3.76 \mathrm{~m} / \mathrm{s}$.

A 2D resistivity survey was conducted with a Syscal R2 (Iris Instruments, Orleans, France) resistivity meter with a Wenner-Schlumberger array with 48 electrodes lined up on the soil surface for a total length of $47 \mathrm{~m}$ and with an electrode spacing of $1.0 \mathrm{~m}$.

A GPR survey was also carried out on the same survey lines by using an acquisition module GSSI SIR 2000 equipped with a $400 \mathrm{MHz}$ antenna and having survey cart and encoder.

In 2D ERT sections (Fig. 5), resistivity ranged between 30 and $400 \Omega \mathrm{m}$, up to a depth of about $5 \mathrm{~m}$. The highest resistivity values (from 80 to $400 \Omega \mathrm{m}$ ) can be associated to the presence of resistive structures with values above $100 \Omega \mathrm{m}$. Conversely, the lowest resistivity values (from 30 to $80 \Omega \mathrm{m}$ ) could be attributed to a higher water and/or clay content. In addition, at about $3.0 \mathrm{~m}$ depth, the 2D tomogram shows a low-resistivity feature than can be ascribed to the groundwater table with overlying capillary fringe.

The radargram corresponding to the ERT profile shows a higher attenuation of the signal in the right side, and this can be associated to increased soil water. Conversely, the left side of the radargram shows a continuous series of reflectors and can be related to the presence of discontinuities like stones or compacted soil.

The three maps of resistivity from ARP (Fig. 6) show that resistive areas are mostly concentrated in southern part of the field, while an area of low resistivity is discernible in the north-eastern area of the field. Summary statistics of soil electrical resistivity measured at the three consecutive depths are reported in Table 4.

Buvat and coauthors (2014) used the multi-depth resistivity dataset to develop a "geophysical taxonomy" based on the vertical succession of the three apparent resistivity values. They found that the resistivity-based clusters well matched soil pedological profiles and were consistent with soil unit boundaries. Following an approach similar to these authors, we used the vertical succession of resistivity values to map soil layering, based on the difference between the resistivity measured in the first $(V 1)$ and in the second layer (V2) values, which were grouped into three classes: D (decreasing values), C (constant values), and I (increasing values). The geophysical taxa show distinct clusters following a north-south gradient. ER increased with depth predominantly in the southern half of the field while it decreases in the northern corner (Fig. 7).

At the adopted imaging resolution and at this time of the year (about 6 months after tillage) we didn't distinguish any spatial pattern related to tillage type, which splits the field longitudinally in two blocks; instead the presence of a structured spatial pattern underlies the necessity of accounting for soil spatial variability in evaluating tillage effects. ER varied from 18 to peak values of about $200 \Omega \mathrm{m}$; highest values were found in the third layer. This range of values can be attributed to different soil features (Samouelian et al. 2005) hence, as in all geophysical exploration, map interpretation requires ground-truth calibration. 
a

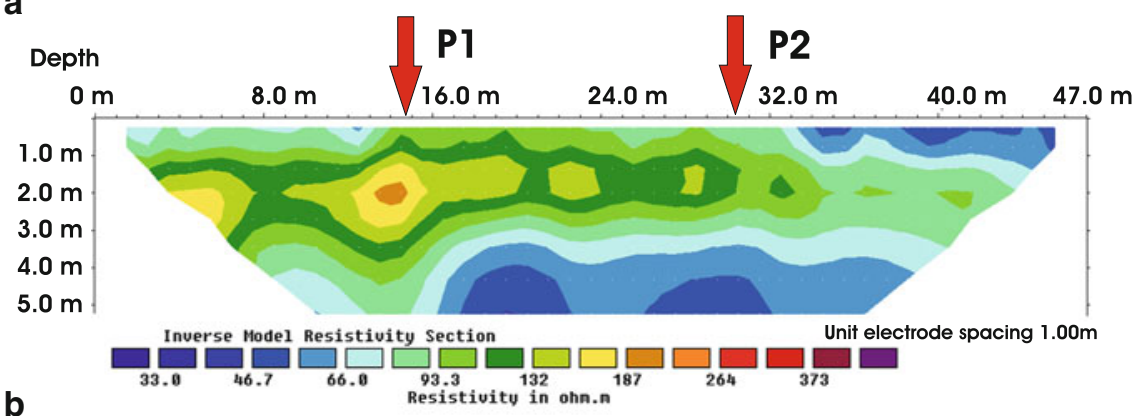

$0 \mathrm{~m}$

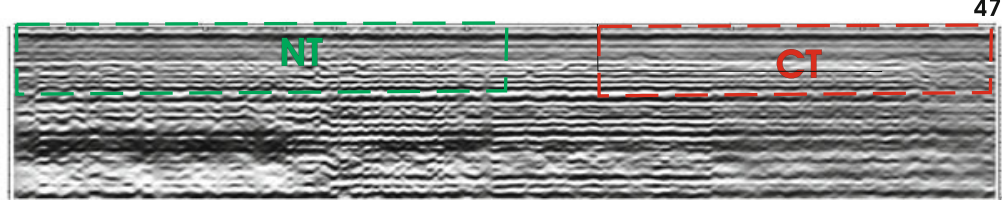

Fig. 5 (a) 2D tomogram of electrical resistivity measured in the experimental field, P1 and P2 arrows point the management systems, respectively, $\mathrm{P} 1=$ No Tillage and $\mathrm{P} 2$ conventional tillage. (b) GPR Radargram carried out in the same direction of resistivity profile in the two management systems ( $N T$ no tillage and $C T$ conventional tillage)

Other studies where a combination of geophysical techniques have been applied are related to coastal areas as shown in the work of Nowroozi et al. (1999), Abdul Nassir et al. (2000), Choudhury and Saha (2004), Sherif et al. (2006), Khalil (2006), Cimino et al. (2008). In the characterization of the coastal saltwater intrusion in the Metapontum forest reserve, Satriani et al. (2012a) used ER tomography alone to highlight the spatial distribution of saline water in the pine forest (Fig. 8)

Geophysical prospecting has an important field of application in archaeology. Loperte et al. (2011) used an integrated geophysical approach based on magnetic, Ground-Penetrating Radar, and geoelectrical survey to investigate a construction work site in the Greek and Roman settlement of Paestum, southern Italy (Fig. 9). The survey showed features that could be ascribed to archaeological remains, as was confirmed by subsequent excavations where walls, canals, and tombs were found.

The high potential of geophysical survey in agriculture has been now recognized; over the last decade geophysical sensors based on the nondestructive measurement of soil electrical conductivity (or its inverse resistivity) have been extensively used in precision agriculture, alone or coupled with terrain information, to help delineating uniform management zones (Peralta et al. 2013; Moral et al. 2010; Kitchen et al. 2005). Using such techniques, we are able to visualize soil features related to their electrical behavior; as current flux in soil is mostly electrolytic, resistivity is very sensitive to the two components that are mainly involved in charge transfer: the degree of pore water saturation and salinity (Lesch 2005) and the specific surfaces associated to the presence of clay particles (Tabbagh et al. 2000). Resistivity is even sensitive to the microstructure of clays, 


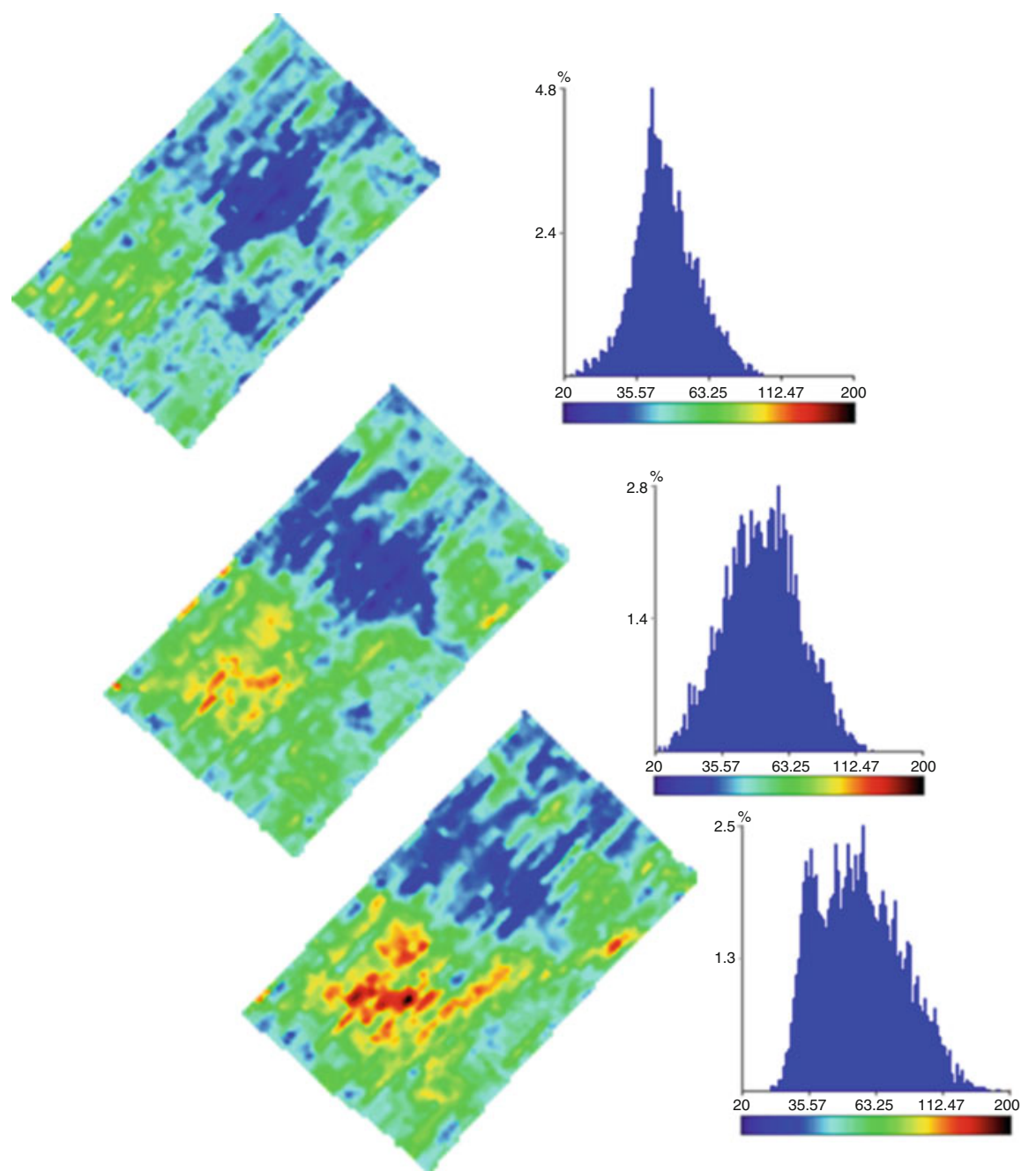

Fig. 6 ARP multi-depth apparent resistivity maps and relative frequency distribution (red shade indicate high values and blue shade depict low values): top $V 1=0-0.5 \mathrm{~m}$ layer, middle $V 2=0-0.1 \mathrm{~m}$ layer, bottom $V 3=0-2 \mathrm{~m}$ layer

based on lab measurements of worldwide collected clay samples; a first database of clays resistivity was compiled by Giao and coauthors (Giao et al. 2003). A soil conductivity survey conducted across different soils showed strong and consistent correlations with clay (Sudduth et al. 2005). This sensitivity is very useful in agricultural soil mapping, since many relevant properties are heavily influenced by and covariate with clay content, such as: water holding capacity, organic matter content, soil structure, temperature, and cation exchange capacity. For the opposite reason resistivity readings can also be used to localize resistive features, that act as 
Table 4 Descriptive statistic of the multi-depth apparent resistivity layers

\begin{tabular}{l|l|l|l}
\hline & $V 1$ & $V 2$ & $V 3$ \\
\hline Mean & 45.24 & 52.43 & 57.80 \\
\hline Median & 42.87 & 49.21 & 51.96 \\
\hline Standard deviation & 12.25 & 17.80 & 23.25 \\
\hline Kurtosis & 1.68 & 0.81 & 2.12 \\
\hline Skeweness & 1.07 & 0.91 & 1.30 \\
\hline Minimum & 18.34 & 18.22 & 23.10 \\
\hline Maximum & 110.46 & 134.54 & 201.84 \\
\hline Number of observations & 54,997 & 54,997 & 54,997 \\
\hline
\end{tabular}

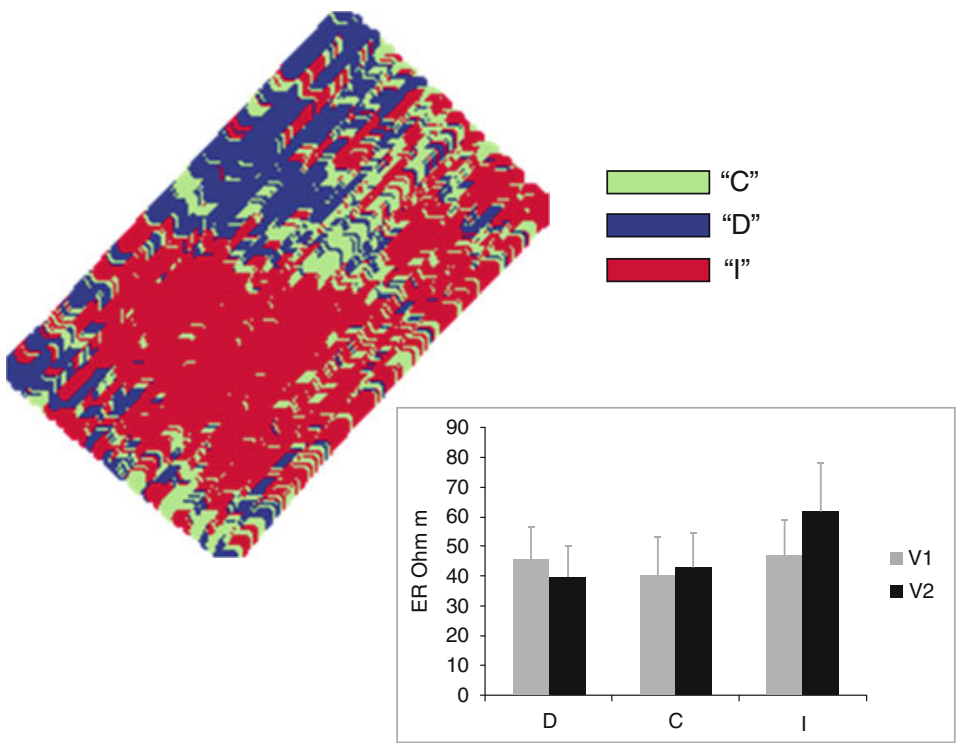

Fig. 7 Bottom left: map of apparent resistivity taxa, based on the difference between the resistivity measured in the first $(V 1)$ and in the second layer $(V 2)$ values were grouped in three classes: $\mathrm{D}$ (decreasing values $=$ blue), $\mathrm{C}$ (constant values $=$ green), and I (increasing values $=$ red). Bottom right: bar plot of V1 (solid gray bar) and V2 (solid black bar) resistivity average values (and relative standard error bars) of the three geophysical taxa $(\mathrm{D}, \mathrm{C}, \mathrm{I})$

barriers to current flux, such as gravel lenses (Tetegan et al. 2012; Rossi et al. 2013b); this is of great value, because of the strong influence that rock fragments exert on soil hydrology, workability, thermal regime, and nutrients pools (Poesen and Lavee 1994) but also because these techniques help filling the well-known methodological gap of quantitative research in stony soils (Eriksson and Holmgren 1996). This extraordinary sensitivity of the technique to the presence of insulating materials constituted the base for the use of the technique for imaging woody plant root system (Amato et al. 2008; Rossi et al. 2011). Plant roots are the key component of plant survivorship and ecology but at the same time are 


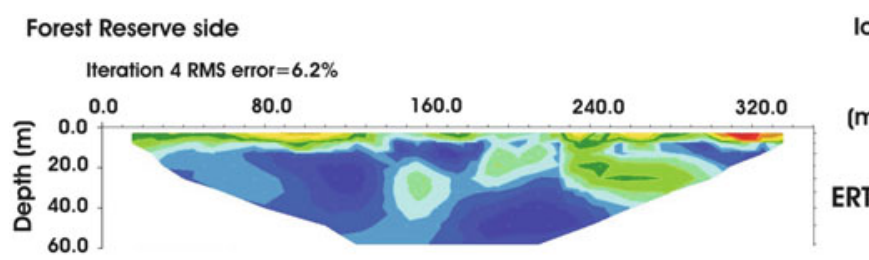

\section{Ionian Sea side}

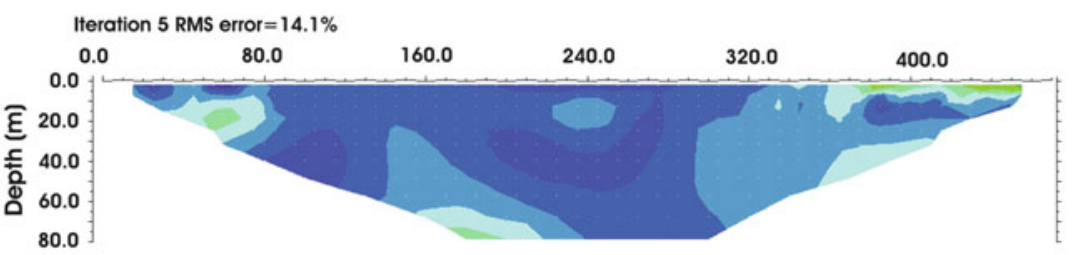

ERT 2

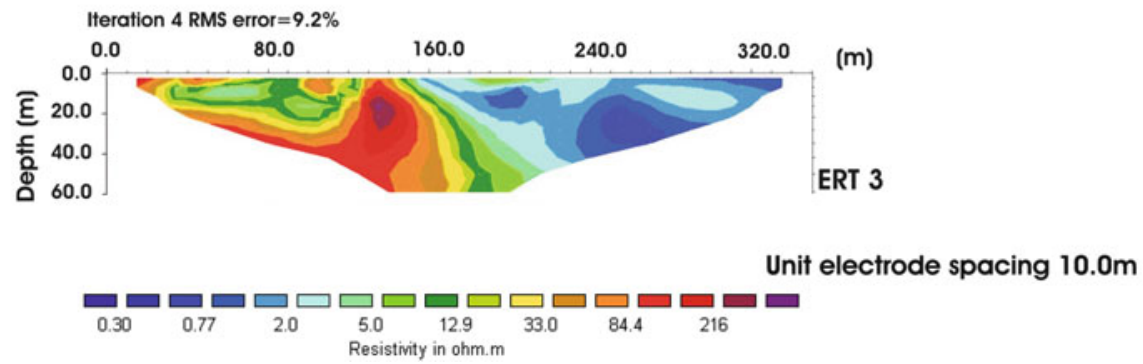

Fig. 8 Electrical resistivity tomograms from the Metapontum forest reserve

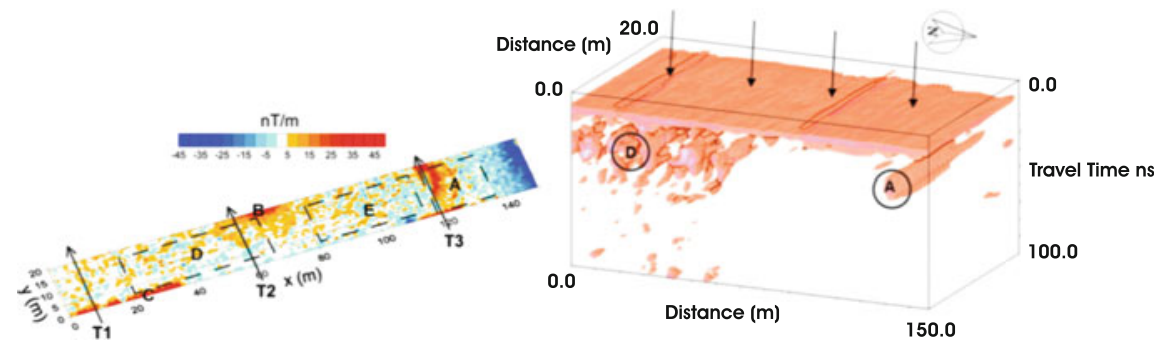

Fig. 9 Map of processed magnetometric results (left) and 3D visualization of GPR prospecting (right) at a construction work site in Paestum (SA). The main electromagnetic anomalies are marked by capital letters while the black arrows indicate the travertine bank

considered the most elusive aspect of belowground studies; this is mainly related to the lack of methodologies to study root systems at the appropriate spatiotemporal scale without interfering with their growth and development (Amato 2004). Quantitative research on the use of resistivity tomography for mapping root system spatial variability has shown that lignified coarse plant roots exhibit a strong electrical response, that rooted soil resistivity can increase several hundred Ohm meter (Amato et al. 2008), and that their effect can be dominating in agricultural 
soil (Rossi et al. 2011). First research on herbaceous roots (Amato et al., 2009) has shown that even at very low density they increase resistivity, but that their resistivity values overlap those of other common soil materials; thus fine roots could only be discerned and quantified keeping the other sources of variability low and unstructured.

A combination of Ground-Penetrating Radar (GPR) and Electrical Resistivity Tomography (ERT) has been used by Satriani et al. (2010) to produce high resolution images that were obtained in laboratory measurements, and they have clearly shown the presence of soil volumes with a high density of fine and woody roots.

Several research reports have shown that resistivity could be used to map permanent soil properties at farm scale (André et al. 2012; Buvat et al. 2014). In some cases, soil texture can dominate the resistivity pattern overshadowing soil structure and water-related properties (Banton et al. 1997). For a given texture, though, soil structural state variation, by altering the proportions between water and air filled porosity, can exert a strong effect on resistivity; this is at the base of the successful use of high resolution resistivity tomography for mapping soil alterations induced by tillage (Besson et al. 2004; Basso et al. 2010). Basso and coauthors (2010) found that resistivity mapping allowed to discern between tilled, freshly tilled, and untilled soils better than penetrometry. Time lapsed resistivity tomography was later used to evaluate soil structural recovery after compaction (Besson et al. 2013). Satriani et al. (2012b) monitored water content and distribution in drybean using resistivity tomography and time-domain reflectometry in two different irrigation treatments with applications for the reduction of water use without reducing yield.

Repeated resistivity measures were also used to infer within-field spatiotemporal organization of soil water, discounting this way the effect of soil texture (Besson et al. 2010). Whether resistivity is going to be used to discern permanent or transient soil properties, some baseline conditions must be satisfied: the target soil property variation must be large enough and must have a sufficient degree of contrast with the surrounding matrix (Banton et al. 1997), and of course the scale of measurements must be proportional to the target. Once these prerequisites are met, map interpretation requires ground-truth calibration, since several soil constituents show overlapping resistivity ranges (Samouelian et al 2005) or offsetting resistive behavior (i.e., rock fragments coated in clay; sandy saline layers) which can lead to ambiguous interpretation. The choice of the sampling strategy is crucial since the high costs of destructive sampling can rapidly counterweight the benefits of using a low-cost ancillary information instead of traditional expensive and labordemanding soil survey methods. The issue of geophysical sensor data groundtruth sampling schemes has been addressed by Lesch (2005) that suggests the use of a model-based sampling strategy as an alternative to probability-based sampling. Model-based or directed sampling instead of relying on randomization principle is focused toward the estimation of a regression model; hence sampling locations are explicitly chosen to cover the full range of the target variable (feature space). Directed sampling strategies typically allow to reduce the number of samples for 
an efficient model parameter estimation (Fitzgerald et al. 2006). Additional spatial optimization criteria can be included to maximize the spread of data to minimize the autocorrelation between observations (Lesch 2005), to reduce the costs of measurements (Minasny and McBratney 2006), or to intensify the number of samples where the variation is large (Minasny et al. 2007).

Acknowledgments This work was partly financed by the Project psr BASILICATA 2007-2013. MISURA 124 "Approcci innovativi per il miglioramento delle performances ambientali e produttive dei sistemi cerealicoli no-Tillage BIO-TILLAGE" CUP C32I14000080006.

Open Access This chapter is distributed under the terms of the Creative Commons Attribution Noncommercial License, which permits any noncommercial use, distribution, and reproduction in any medium, provided the original author(s) and source are credited.

\section{References}

Abdul Nassir SS, Loke MH, Lee CY, Nawawi MNM (2000) Salt-water intrusion mapping by geoelectrical imaging surveys. Geophys Prospect 48:647-661

al Hagrey SA (2007) Geophysical imaging of root-zone, trunk, and moisture heterogeneity. J Exp Bot 58:839-854

Allred B, Daniels JJ, Reza Ehsani M (2008) Handbook of agricultural geophysics. CCR Press, Boca Raton, FL, 410 pp

Amato M (2004) La radice: rappresentazioni e metodi di studio della metà invisibile delle piante. In: Amato M, Migliozzi A, Mazzoleni S (eds) Il sistema suolo - vegetazione. Liguori Editore, Napoli, pp 3-16

Amato M, Basso B, Celano G, Bitella G, Morelli G, Rossi R (2008) In situ detection of tree root distribution and biomass by multi-electrode resistivity imaging. Tree Physiol 28:1441-1448

Amato M, Bitella G, Rossi R, Gómez JA, Lovelli S, Ferreira Gomes JJ (2009) Multi-electrode 3-D resistivity imaging of alfalfa root zone. Eur J Agron 31: 216-222

André F, van Leeuwen C, Saussez S, Van Durmen R, Bogaert P, Moghadas D, de Rességuier L, Delvaux B, Vereecken H, Lambot S (2012) High-resolution imaging of a vineyard in south of France using ground-penetrating radar, electromagnetic induction and electrical resistivity tomography. J Appl Geophys 78:113-122

Banton O, Cimon MA, Seguin MK (1997) Mapping field-scale physical properties of soil with electrical resistivity. Soil Sci Soc Am J 61:1010-1017

Basso B, Amato M, Bitella G, Rossi R, Kravchenko A, Sartori L et al (2010) Two-dimensional spatial and temporal variation of soil physical properties in tillage systems using electrical resistivity tomography. Agron J 102:440-449

Besson A, Cousin I, Samouelian A, Boizard H, Richard G (2004) Structural heterogeneity of the soil tilled layer as characterized by 2D electrical resistivity surveying. Soil Tillage Res 79:239-249

Besson A, Cousin I, Bourennane H, Nicoullaud B, Pasquier C, Richard G, Dorigny A, King D (2010) The spatial and temporal organization of soil water at the field scale as described by electrical resistivity measurements. Eur J Soil Sci 61:120-132

Besson A, Séger M, Giot G, Cousin I (2013) Identifying the characteristic scales of soil structural recovery after compaction from three in-field methods of monitoring. Geoderma 204-205:130-139

Brevik EC, Fenton TE, Lazari A (2003) Differences in EM-38 readings taken above crop residues versus readings taken with instrument-ground contact. Precis Agric 4:351-358 
Buvat S, Thiesson J, Michelin J, Nicoullaud B, Bourennane H, Coquet Y, Tabbagh A (2014) Multi-depth electrical resistivity survey for mapping soil units within two 3 ha plots. Geoderma 232:317-327

Calamita G, Brocca L, Perrone A, Lapenna V, Moramarco T, Piscitelli S (2012) Electrical resistivity and TDR methods for soil moisture estimation in central Italy test-sites. J Hydrol 454:101-112

Chianese D, Lapenna V (2007) Magnetic probability tomography for environmental purposes: test measurements and field applications. J Geophys Eng 4:63-74

Choudhury K, Saha DK (2004) Integrated geophysical and chemical study of saline water intrusion. Ground Water 42:671-677

Cimino A, Cosentino C, Oieni A, Tranchina L (2008) A geophysical and geochemical approach for seawater intrusion assessment in the Acquedolci coastal aquifer (Northern Sicily). Environ Geol 55:1473-1482

Conyers LB, Goodman D (1997) Ground-penetrating radar: an introduction for archaeologists. Altamira, London

Corwin DL, Lesch SM (2005) Apparent soil electrical conductivity measurements in agriculture. Comput Electron Agric 46:11-43

Corwin DL, Plant RE (2005) Applications of apparent soil electrical conductivity in precision agriculture. Comput Electron Agric 46:1-10

Dabas M, Tabbagh A (2003) A comparison of EMI and DC methods used in soil mappingtheoretical considerations for precision agriculture. In: Stafford J, Werner A (eds) Precision agriculture. Wageningen Academic, Wageningen, pp 121-127

Daniels JJ (2002) Updated 'GPHYZ' IDL 5.5 for GPR interpretation [internet]. http://www. geology.ohio-state.edu/ jeff/

Daniels D (2004) Ground penetrating radar, vol 2. The Institution of Electrical Engineers (IEE), London

Edlefsen NE, Anderson AB (1941) The four-electrode resistance method for measuring soilmoisture content under field conditions. Soil Sci 51:367-376

Edwards LS (1977) A modified pseudosection for resistivity and IP. Geophysics 42:1020-1036

Environmental Indicator Report (2013) Natural resources and human well-being. In: A Green economy [internet]. EEA, Copenhagen. http://www.eea.europa.eu/publications/environmen tal-indicator-report-2013

Eriksson CP, Holmgren P (1996) Estimating stone and boulder content in forest soils-evaluating the potential of surface penetration methods. Catena 28:121-134

Field C, Barros V, Dokken D, Mach K, Mastrandrea M, Billir T, Chatterjee M, Ebi K, Estrada Y, Genova R (2014) Climate change 2014: impacts, adaptation, and vulnerability. Part a: global and sectoral aspects. Contribution of working group II to the fifth assessment report of the intergovernmental panel on climate change. Cambridge University Press, Cambridge

Fitzgerald GJ, Lesch SM, Barnes EM, Luckett WE (2006) Directed sampling using remote sensing with a response surface sampling design for site-specific agriculture. Comput Electron Agric 53:98-112

Giao P, Chung S, Kim D, Tanaka H (2003) Electric imaging and laboratory resistivity testing for geotechnical investigation of Pusan clay deposits. J Appl Geophys 52:157-175

Greenhouse JP (1991) Environmental geophysics: it's about time. Lead Edge 10:32-34

Hubbard S, Grote K, Rubin Y (2002) Mapping the volumetric soil water content of a California vineyard using high-frequency GPR ground wave data. Lead Edge 21:552-559

Kearey P, Brooks M, Hill I (2002) An introduction to geophysical exploration, 3rd edn. Blackwell Science, Oxford

Khalil MH (2006) Geoelectric resistivity sounding for delineating salt water intrusion in the Abu Zenima area, west Sinai. J Geophys Eng 3:243-251

Kitchen NR, Sudduth KA, Myers DB, Drummond ST, Hong SY (2005) Delineating productivity zones on claypan soil fields using apparent soil electrical conductivity. Comput Electron Agric 46:285-308 
Lesch SM (2005) Sensor-directed response surface sampling designs for characterizing spatial variation in soil properties. Comput Electron Agric 46:153-179

Loke MH (2001) Tutorial: 2-D and 3-D electrical imaging surveys. In: Course notes for USGS workshop 2-D and 3-D inversion and modeling of surface and borehole resistivity data, Torrs, CT

Loke MH, Barker RD (1996) Rapid least-squares inversion of apparent resistivity pseudosections by a quasi-Newton method. Geophys Prospect 44:131-152

Loperte A, Satriani A, Bavusi M, Lapenna V, Dellungo S, Sabelli R, Gizzi FT (2011) Geophysical prospecting in archaeology: investigations in SantaVenera, south suburb of PoseidoniaPaestum, Campania, southern Italy. J Geophys Eng 8:23-32

Michot D, Benderitter Y, Dorigny A, Nicoullaud B, King D, Tabbagh A (2003) Spatial and temporal monitoring of soil water content with an irrigated corn crop cover using electrical resistivity tomography. Water Resour Res 39:1138

Minasny B, McBratney AB (2006) A conditioned Latin hypercube method for sampling in the presence of ancillary information. Comput Geosci 32:1378-1388

Minasny B, McBratney AB, Walvoort DJ (2007) The variance quadtree algorithm: use for spatial sampling design. Comput Geosci 33:383-392

Moral FJ, Terrón JM, Silva JRM (2010) Delineation of management zones using mobile measurements of soil apparent electrical conductivity and multivariate geostatistical techniques. Soil Tillage Res 106:335-343

Nowroozi A, Horrocks SB, Henderson P (1999) Saltwater intrusion into the freshwater aquifer in the eastern shore of Virginia: a reconnaissance electrical resistivity survey. J Appl Geophys 42:1-22

Panissod C, Dabas M, Jolivet A, Tabbagh A (1997) A novel mobile multipole system (MUCEP) for shallow (0-3 m) geoelectrical investigation: the 'Vol-de-canards' array. Geophys Prospect 45:983-1002

Peralta NR, Costa JL, Balzarini M, Angelini H (2013) Delineation of management zones with measurements of soil apparent electrical conductivity in the Southeastern Pampas. Can J Soil Sci 93:205-218

Poesen J, Lavee H (1994) Rock fragments in top soils: significance and processes. Catena 23:1-28

Rhoades JD, Ingvalson RD (1971) Determining salinity in field soils with soil resistance measurements. Soil Sci Soc Am J 35:54-60

Rossi R, Amato M, Bitella G, Bochicchio R, Ferreira Gomes JJ, Lovelli S et al (2011) Electrical resistivity tomography as a non-destructive method for mapping root biomass in an orchard. Eur J Soil Sci 62:206-215

Rossi R, Pollice A, Diago M, Oliveira M, Millan B, Bitella G et al (2013a) Using an automatic resistivity profiler soil sensor on-the-go in precision viticulture. Sensors 13:1121-1136

Rossi R, Amato M, Pollice A, Bitella G, Gomes JJ, Bochicchio R et al (2013b) Electrical resistivity tomography to detect the effects of tillage in a soil with a variable rock fragment content. Eur $\mathrm{J}$ Soil Sci 64:239-248

Rubin Y, Hubbard SS (2006) Hydrogeophysics. Water Science and Technology Library. Springer, Dordrecht

Samouelian A, Cousin I, Richard G, Tabbagh A, Bruand A (2003) Electrical resistivity imaging for detecting soil cracking at the centimetric scale. Soil Sci Soc Am J 67:1319-1326

Samouelian A, Cousin I, Tabbagh A, Bruand A, Richard G (2005) Electrical resistivity survey in soil science: a review. Soil Tillage Res 83:173-193

Satriani A, Loperte A, Proto M, Bavusi M (2010) Building damage caused by tree roots: laboratory experiments of GPR and ERT surveys. Adv Geosci 24:133-137

Satriani A, Loperte A, Imbrenda V, Lapenna V (2012a) Geoelectrical surveys for characterization of the coastal saltwater intrusion in Metapontum forest reserve (southern italy). Int J Geophys 2012:1-8

Satriani A, Loperte A, Catalano M (2012b) Non-invasive instrumental soil moisture monitoring on a typical bean crop for an irrigation sustainable management. Int Water Technol J 2:309-320 
Sherif M, El Mahmoudi A, Garamoon H, Kacimov A (2006) Geoelectrical and hydrogeochemical studies for delineating seawater intrusion in the outlet of WadiHam, UAE. Environ Geol 49:536-551

Sheriff RE (1991) Encyclopedic dictionary of exploration geophysics, 3rd edn. Society of Exploration Geophysicists, Tulsa

Soldovieri F, Crocco L, Brancaccio A, Solimene R, Persico R (2011) Applications of ground penetrating radar and microwave tomography in water monitoring and management. Int Water Technol J 1:78-88

Soueid Ahmed A, Jardani A, Revil A, Dupont JP (2013) A 2D forward and inverse code for streaming potential problems. Comput Geosci 59:9-16

Steeples D (1991) Uses and techniques of environmental geophysics. Lead Edge 19:30-31

Steeples DW (2001) Engineering and environmental geophysics at the millennium. Geophysics $66: 31-35$

Sudduth K, Kitchen NR, Wiebold WJ, Batchelor WD, Bollero G, Bullock DG et al (2005) Relating apparent electrical conductivity to soil properties across the north-central USA. Comput Electron Agric 46:263-283

Tabbagh A, Dabas M, Hesse A, Panissod C (2000) Soil resistivity: a non-invasive tool to map soil structure horizonation. Geoderma 97:393-404

Tetegan M, Pasquier C, Besson A, Nicoullaud B, Bouthier A, Bourennane H (2012) Field-scale estimation of the volume percentage of rock fragments in stony soils by electrical resistivity. Catena 92:67-74

Vereecken H, Binley A, Cassiani G, Revil A, Titov K (2006) Applied hydrogeophysics. In: Revil A, Titov K (eds) NATO science series IV: earth and environmental sciences. Springer, Dordrecht, $\mathrm{p} 383$

Werban U, al Hagrey S, Rabbel W (2008) Monitoring of root-zone water content in the laboratory by 2D geoelectrical tomography. J Plant Nutr Soil Sci 171:927-935 